\title{
EFEITO DE DIFERENTES TEORES DE ESTERCO BOVINO E NÍVEIS DE SALINIDADE NO CRESCIMENTO INICIAL DA MAMONEIRA (Ricinus communis L.)
}

\author{
Mychelle Karla Teixeira Oliveira \\ Bolsista PIBIC/UFERSA, UFERSA, Mossoró - RN mychellekarla.oliveira@bol.com.br \\ Francisco de Assis de Oliveira \\ Mestrando em Irrigação e Drenagem, UFERSA, Mossoró - RN. thikaoamigao@bol.com.br \\ José Francismar de Medeiros \\ Bolsista CNPq, Engo ${ }^{\circ}$ gro $^{\circ}$, Dr., Depto. Ciências Ambientais, UFERSA, Mossoró - RN \\ Carlos José Gonçalves de Souza Lima \\ Bolsista PIBIC/UFERSA, Graduando Agronomia, UFERSA, Mossoró - RN \\ Isaias Porfírio Guimarães \\ Eng $^{\circ}$ Agr $^{\circ}$,Mestrando em Irrigação e Drenagem, Depto. Ciências Ambientais, UFERSA, Mossoró - RN
}

\begin{abstract}
RESUMO: Este trabalho teve como objetivo avaliar o efeito da irrigação com água de diferentes salinidade e diferentes teores de esterco bovino no crescimento inicial da mamoneira. O experimento foi conduzido na Universidade Federal Rural do Semi-Árido, Mossoró - RN, em blocos casualizados num esquema fatorial $4 \times 4$, com três repetições e uma planta/vaso por parcela. Foram utilizados quatro níveis de salinidade $\left(S_{1}=0,5 ; S_{2}=2,0\right.$; $\mathrm{S}_{3}=4,0$ e $\left.\mathrm{S}_{4}=6,0\right)$, em $\mathrm{dS} \mathrm{m} \mathrm{m}^{-1}$, ajustados em água proveniente de poço profundo, através da adição de $\mathrm{NaCl}$ na água de irrigação, com quatro teores de esterco bovino no substrato $\left(\mathrm{E}_{1}=0\right.$; $E_{2}=3: 1 ; E_{3}=2: 1 ;$ e $E_{4}=1: 1$ ). As variáveis avaliadas foram: número de folhas (NF), área foliar (AF), diâmetro do caule (DC), altura (ALT), fitomassa seca da raiz (FSR) e fitomassa seca da parte aérea (FSPA) aos 64 dias após semeadura (DAS). Todas as variáveis foram afetadas pelos fatores estudados, sendo o efeito isolado dos níveis salinos e dos teores de esterco, sem, entretanto haver variação significativa na interação (SxE). Os resultados demostraram que o crescimento da mamoneira foi afetado negativamente pela salinidade da água acima de 4dS $\mathrm{m}^{-1}$ e positivamnte pelos teores de esterco bovino.
\end{abstract}

Palavras chave: Ricinus communis L., irrigação, adubação orgânica.

\section{EFFECTS OF DIFFERENT PROPORTIONS OF MANURE BOVINE AND SALINITY LEVELS IN THE GROWTH INDEXES ON THE CASTORBEAN (Ricinus communis L.)}

\begin{abstract}
The aim of this work to evaluate the effects of irrigation with waters of different salinity levels and proportions of manure bovine in the growth indexes of the castorbean. The experiment was carried out at University Federal Rural of Semi - Arid, Mossoró - RN, in a randomized blocks in a factorial scheme $(4 \times 4)$, with three replications a
\end{abstract}

Revista Verde (Mossoró - RN - Brasil) v.1, n.1, p. 47-53 janeiro/junho de 2006

http://revista.gvaa.com.br 


\section{REVISTA VERDE DE AGROECOLOGIA E DESENVOLVIMENTO SUSTENTÁVEL GRUPO VERDE DE AGRICULTURA ALTERNATIVA (GVAA)}

one plant/vase by plot. Four water salinity levels $\left(S_{1}=0,5 ; S_{2}=2,0 ; S_{3}=4,0\right.$ e $S_{4}=6,0$, em dS m ${ }^{1}$ ), adjusted through the addition of $\mathrm{NaCl}$ with four proportion of manure bovine in the substrates $\left(E_{1}=0 ; E_{2}=3: 1 ; E_{3}=2: 1 ;\right.$ e $\left.E_{4}=1: 1\right)$. The variables appraised were: number of leaves, leaf area, stems diameter, height plant, phytomass of the aerial parts and phytomass of the root at 64 days after sowing. Every the variables was found to be affected by the studies factors, by saline levels and proportions of manure, without, any significant variation in the interaction (SxE). The results showed that the salinity of waters of irrigation from $4,0 \mathrm{dS} \mathrm{m}^{-1}$ and positive in the proportions of manure bovine.

Key words: Ricinus communis L., irrigation, assess organic.

\section{INTRODUÇÃO}

Pertencente à família Euphorbiaceae, que engloba um vasto número de espécies nativas da região tropical, a mamona (Ricinus communis L.) possui em seus subprodutos compostos químicos de grande interesse industrial. O óleo extraído de suas sementes possui propriedades químicas especiais, podendo ser utilizado como ingrediente na fabricação de lubrificantes para aviões a jato, fluidos hidráulicos, no preparo de tintas, vernizes e plásticos.

A cultura da mamona vem se destacando como uma das mais promissoras entre os pequenos produtores, especialmente no Semi-Árido nordestino, por apresentar características importantes como resistência a seca e ser rica fonte da matéria-prima indispensável para a fabricação do biodíesel, constituindo assim numa ferramenta de suma importância para o desenvolvimento do Brasil. Pode ser encontrada praticamente em todo Nordeste, cujas condições climáticas são propícias ao seu desenvolvimento e crescimento (EMBRAPA, 2006). O Brasil ocupa o $5^{\circ}$ lugar em produção e o segundo exportador mundial, oferecendo como vantagem, um óleo de alta qualidade, tornando o país mais competitivo (CONAB, 2004). Essa cultura tem-se comportado de forma resistente ao clima, em condições onde outras culturas poderiam sofrer perda total, assim é uma boa alternativa de trabalho e renda para o agricultor da região.

A mamoneira é uma planta exigente em fertilidade, bem como em aeração para suas raízes, apresentando drástica redução no crescimento quando submetida a condições adversas. Entre as principais técnicas aplicadas para aumentar a produtividade e a rentabilidade, destaca-se a adubação, em especial a adubação orgânica. No entanto, mesmo sendo a mamoneira exigente em fertilidade do solo, ainda existe uma certa carência quanto a pesquisas busca de adequação na adubação desta cultura. Para Stewart \& Robinson (1997), a manutenção e incorporação da matéria orgânica no solo é um dos principais fatores limitantes ao desenvolvimento da sustentabilidade nas regiões Semi-Áridas. Segundo Filgueira (2000), o esterco bovino eleva a CTC, proporciona retenção de umidade e de nutrientes, como o nitrogênio, elemento responsável pelo crescimento da parte aérea das hortaliças.

O uso da água salina na agricultura deve ser considerada como uma alternativa importante na utilização dos recursos naturais escassos, como a água. Neste sentido, devese garantir o seu uso através de um manejo 


\section{REVISTA VERDE DE AGROECOLOGIA E DESENVOLVIMENTO SUSTENTÁVEL GRUPO VERDE DE AGRICULTURA ALTERNATIVA (GVAA)}

cuidadoso (RHOADES et al., 2000). No entanto a qualidade das águas da região Nordeste que podem ser usadas na irrigação é muito variável, tanto em termos geográficos como ao longo do ano, principalmente nos pequenos reservatórios, onde a salinidade aumenta consideravelmente com a redução do volume armazenado. Para Audry \& Suassuna (1990) o uso intenso dessas águas pode provocar redução no potencial produtivo da cultura, além de sérios riscos de salinização dos solos.

A acumulação gradativa de sais solúveis no solo, sobretudo na zona das raízes, reduz o crescimento e o desenvolvimento das plantas por baixar o potencial osmótico da solução do solo, causando estresse hídrico e, também, por ocasionar problemas de toxicidade e de desordem nutricional (FAGERIA, 1989; SHANNON, 1997). O estresse salino representa um dos mais sérios fatores a limitar o crescimento e a produção das culturas, induzindo as modificações morfológicas, estruturais e metabólicas nas plantas superiores (IZZO et al., 1991),

As espécies vegetais apresentam diferentes respostas à salinidade, diferindo inclusive entre genótipos de uma mesma espécie. Essa variabilidade genética permite a seleção de espécies e cultivares mais tolerantes, capazes de atingir rendimentos economicamente viáveis, em condições de salinidade elevada (AYERS \& WESTCOT, 1991). Esses mesmos autores relatam que a tolerância à salinidade pode variar também de acordo com o estágio de desenvolvimento das plantas, sendo mais sensíveis na fase inicial de desenvolvimento.

Diante do exposto, este trabalho teve como objetivo avaliar o crescimento inicial da mamoneira quando submetida a diferentes teores de esterco bovino e níveis de salinidade.

\section{MATERIAL E MÉTODOS}

O experimento foi conduzido nas dependências da Biofábrica do Departamento de Ciências Vegetais da Universidade Federal Rural do Semi-Árido (UFERSA), localizada nas coordenadas geográficas de $5^{\circ}$ $11^{\prime} 31^{\prime \prime}$ de latitude sul e $37^{\circ} 20^{\prime} 40^{\prime \prime}$ de longitude oeste de Greenwich, com altitude média de $18 \mathrm{~m}$. O clima local é do tipo BSwh'com base na classificação de Köppen e a média anual de precipitação é da ordem de $678 \mathrm{~mm}$. As médias anuais de temperatura, insolação e umidade relativa são $27,4^{\circ} \mathrm{C}, \quad 236$ horas anuais e 68,9\% respectivamente (AMARO FILHO, 1991).

Utilizou-se o delineamento em blocos casualizados num esquema fatorial $4 \times 4 \mathrm{com}$ três repetições, sendo 0 primeiro fator constituído de diferentes teores de esterco bovino e o segundo de diferentes níveis de salinidade. Os tratamentos foram compostos das diferentes combinações desses fatores, num total de 16 (Tabela 1). A unidade experimental foi representada por uma planta /vaso.

Tabela 1 - Relação das diferentes combinações dos teores de esterco e níveis de salinidades usadas no experimento

\begin{tabular}{ccccc}
\hline \multirow{2}{*}{ Teores de esterco } & \multicolumn{4}{c}{ Níveis de salinidade } \\
\cline { 2 - 5 } & $\mathrm{S} 1=0,5 \mathrm{ds} \mathrm{m}^{-1}$ & $\mathrm{~S} 2=2 \mathrm{ds} \mathrm{m}^{-1}$ & $\mathrm{~S} 3=4 \mathrm{ds} \mathrm{m}^{-1}$ & $\mathrm{~S}_{4}=6 \mathrm{ds} \mathrm{m}^{-1}$ \\
\hline Solo (E1) & E1 S1 & E1 S2 & E1 S3 & E1 S4
\end{tabular}

\footnotetext{
Revista Verde (Mossoró - RN - Brasil) v.1, n.1, p. 47-53 janeiro/junho de 2006
}

http://revista.gvaa.com.br 


\section{REVISTA VERDE DE AGROECOLOGIA E DESENVOLVIMENTO SUSTENTÁVEL GRUPO VERDE DE AGRICULTURA ALTERNATIVA (GVAA)}

\begin{tabular}{lllll}
\hline & & & & \\
Solo + esterco (3:1) (E2) & E2 S1 & E2 S2 & E2S3 & E2 S4 \\
Solo + esterco (2:1) (E3) & E3 S1 & E3 S2 & E3 S3 & E3 S4 \\
Solo + Esterco (1:1) (E4) & E4 S1 & E4 S2 & E4 S3 & E4 S4 \\
\hline
\end{tabular}

Os substratos foram preparados de acordo com os tratamentos estudados, peneirados em malha de $2 \mathrm{~mm}$ e em seguida misturados conforme os teores avaliados e em seguida analisados químicamente (Tabela 2).

Tabela 2 - Resultado das análises químicas dos substratos utilizados no experimento

\begin{tabular}{|c|c|c|c|c|c|c|c|c|}
\hline \multicolumn{9}{|c|}{ Análise Química } \\
\hline Substratos* & $\mathrm{pH}$ & $\mathrm{CE}$ & $\begin{array}{c}\mathrm{P} \\
\mathrm{mg} \mathrm{dm^{3 }}\end{array}$ & $\mathrm{K}^{+}$ & $\mathrm{Na}^{+}$ & $\begin{array}{c}\mathrm{Ca}^{2+} \\
\mathrm{mol}_{\mathrm{c}} \mathrm{d}\end{array}$ & $\mathrm{Mg}^{2+}$ & Al \\
\hline E1 & 6,9 & 0,7 & 35,61 & 0,27 & 0,11 & 4,1 & 2,0 & 0,0 \\
\hline E2 & 7,4 & 2,95 & 430,29 & 2,19 & 1,43 & 8,0 & 4,1 & 0,0 \\
\hline E3 & 7,2 & 4,2 & 734,18 & 2,35 & 1,19 & 9,0 & 1,2 & 0,0 \\
\hline E4 & 7,1 & 5,4 & 658,13 & 2,60 & 1,27 & 6,5 & 6,0 & 0,0 \\
\hline
\end{tabular}

*E1 = solo, E2 = Solo + esterco (3:1), E3 = Solo + Esterco (2:1) e E4 = Solo + Esterco (1:1)

A semeadura foi realizada no dia 06/08/2006 em vasos de $2 \mathrm{dm}^{3}$, num total de quatro sementes da variedade BRS 149Nordestina por vaso. Para acelerar a germinação foi realizada a retirada da carúncula (OLIVEIRA, 2004), dez dias após a emergência fez-se o desbaste, deixando apenas a plântula mais vigorosa.

Os níveis de salinidade aplicados foram obtidos a partir da adição de $\mathrm{NaCl}$ em água, onde o nível $0,5 \mathrm{dS} \mathrm{m}^{-1}$, correspondeu à água usada na dissolução dos demais, sendo esta água captada no poço localizado no campus da UFERSA. A irrigações foram realizadas duas vezes ao dia, deixando os substratos sempre próximos as capacidades de campo.

Aos 64 dias após a semeadura as plantas foram coletadas e analisadas. As variáveis avaliadas foram: número de folhas (NF), sendo consideradas apenas as folhas ativas, área foliar (AF) utilizando para isto o integrador de área foliar, modelo LI-3100 da Licor, diâmetro do caule (DC), medido através de um paquímetro, altura (ALT), medida com uma régua graduada em $\mathrm{cm}$, fitomassa seca da raiz (FSR) e fitomassa seca da parte aérea (FSPA), ambas em gramas, para tais, as plantas foram acondicionadas em sacos de papel e postas para secar em estufa de circulação forçada, à temperatura de $70^{\circ} \mathrm{C}$ $\pm 1^{\circ} \mathrm{C}$ até atingir peso constante, em seguidas foram pesadas em balança analítica de precisão $0,01 \mathrm{~g}$. Os resultados obtidos foram submetidos às análises de variância e de regressão, utilizando-se o software SAEG versão 8.0 (RIBEIRO JÚNIOR, 2001).

\section{RESULTADOS E DISCUSSÃO}

Não foi verificado efeito significativo na interação entre os fatores estudados (dados não mostrados), desta forma os mesmos foram avaliados isoladamente. Avaliando-se o fator teor de esterco, a análise de variância pelo teste $F$ verificou feito significativo para todas as características avaliadas, sendo a significância de $(\mathrm{p}<0,05)$ para a variável fitomassa seca da raiz e de 


\section{REVISTA VERDE DE AGROECOLOGIA E DESENVOLVIMENTO SUSTENTÁVEL GRUPO VERDE DE AGRICULTURA ALTERNATIVA (GVAA)}

$(\mathrm{p}<0,01)$ para as demais variáveis (Tabela 3). As médias foram comparadas pelo teste de Tukey $(\mathrm{p}<0,05)$, (Tabela 3). Para o número de folhas (NF) observa-se efeito positivo do esterco, onde o maior valor foi obtido com o maior teor de esterco bovino (1:1), enquanto que o menor valor foi obtido com o tratamento na ausência do esterco. Com relação à área foliar (AF) verifica-se resposta semelhante ao número de folhas, ficando os menores valores na ausência do esterco e os maiores valores no tratamento com o maior teor (1:1), os tratamentos intermediários não diferiram entre si. Para o diâmetro do caule (DC) e altura das plantas (ALT), apenas o tratamento sem o esterco diferiu dos demais, obtendo o menor desempenho. A fitomassa seca da raiz foi influenciada pelo aumento no teor do esterco, onde os melhores desempenhos foram proporcionados pelos tratamentos com os maiores teores do esterco. Para a fitomassa seca da parte aérea, o pior desempenho foi obtido sem esterco, enquanto que o maior foi obtido no tratamento com o maio teor de esterco (1:1), os tratamentos com teores de esterco intermediários não diferiram entre si. Estes resultados assemelham-se aos obtidos por Pontes (1991), que trabalhando com mudas de mamão, verificou que a adição de esterco na composição de substrato apresentou efeitos benéficos para altura, comprimento das raízes, diâmetro do colo e peso da matéria seca das raízes. O efeito positivo do esterco bovino sobre o desenvolvimento das plantas se deve não somente ao suprimento de nutrientes, mas também, a melhoria da fertilidade e da estrutura do solo, e no fornecimento de água, proporcionando melhor aproveitamento dos nutrientes originalmente presentes (Filgueira, 2000).

Lima et al. (2006) verificou resultados resposta positiva em mudas de mamona produzidas com substratos contendo produtos orgânicos enquanto que Mendonça et al. (2006) verificou que percentual de $40 \%$ de composto orgânico no substrato para produção de mudas de mamão Formosa pode ser uma alternativa viável

Tabela 3 - Resumo da variância e valores médios para número de folhas (NF), área foliar (AF), diâmetro do caule (DC), altura (ALT), fitomassa seca da raiz (FSR) e fitomassa seca da parte aérea (FSPA) da mamoneira sob diferentes teores de esterco na fase inicial de crescimento. Mossoró - RN, 2006

\begin{tabular}{|c|c|c|c|c|c|c|c|}
\hline \multirow{3}{*}{ Causa da variação } & \multirow{3}{*}{ GL } & \multicolumn{6}{|c|}{ Quadrados médios } \\
\hline & & \multicolumn{6}{|c|}{ Variáveis } \\
\hline & & NF & $\mathrm{AF}$ & $\mathrm{DC}$ & ALT & FSR & FSPA \\
\hline Tratamentos & 3 & $1,639 * *$ & $186216,3^{* *}$ & $4,306^{* *}$ & $231,632 * *$ & $0,279 *$ & $10,427 * *$ \\
\hline Resíduo & 6 & 0,139 & 2521,445 & 0,159 & 6,299 & 0,042 & 0,24 \\
\hline \multirow[t]{2}{*}{ C.V. (\%) } & & 8,44 & 9,14 & 6,23 & 6,55 & 27,13 & 11,85 \\
\hline & \multicolumn{7}{|c|}{ Valores médios } \\
\hline Tratamentos & & NF & $\mathrm{AF}$ & DC & ALT & FSR & FSPA \\
\hline Solo & & $3,67 \mathrm{~b}$ & 243,52 c & $4,67 \mathrm{~b}$ & $25,5 \mathrm{~b}$ & $0,32 \mathrm{~b}$ & 1,73 с \\
\hline Solo + esterco (3:1) & & $4,67 \mathrm{ab}$ & $600,58 \mathrm{~b}$ & 6,67 a & 39,83 a & 0,93 a & $4,07 \mathrm{~b}$ \\
\hline Solo + esterco (2:1) & & $4,00 \mathrm{~b}$ & 506,92 b & 7,05 a & 42,83 a & $0,83 a b$ & $4,47 \mathrm{~b}$ \\
\hline Solo + esterco (1:1) & & 5,33 a & 846,43 a & 7,33 a & $45,12 \mathrm{a}$ & $0,97 \mathrm{a}$ & 6,27 a \\
\hline
\end{tabular}

**, * significativos a $(0,01)$ e $(0,05)$, respectivamente

Médias seguidas da mesma letra não diferem entre si pelo teste de Tukey a 0,05 de probabilidade

Revista Verde (Mossoró - RN - Brasil) v.1, n.1, p. 47-53 janeiro/junho de 2006

http://revista.gvaa.com.br 


\section{REVISTA VERDE DE AGROECOLOGIA E DESENVOLVIMENTO SUSTENTÁVEL GRUPO VERDE DE AGRICULTURA ALTERNATIVA (GVAA)}

Com relação aos níveis de salinidades, a análise de variância realizada pelo teste $\mathrm{F}$ (Tabela 4) verificou resposta significativa $(\mathrm{p}<0,01)$ para todas as características avaliadas para o número de folhas (NF) e altura (ALT), enquanto que para a fitomassa seca da raiz (FSR) e fitomassa seca da parte aérea (FSPA) a significância foi de 0,05 e para a área foliar (AF) e diâmetro do caule não foi encontrada significância. De acordo a tabela 1 , o número de folhas foi afetado pelos níveis de salinidade, sendo seu efeito verificado a partir da salinidade de $4 \mathrm{dS} \mathrm{m} \mathrm{m}^{-1}$, estes resultados refutam aqueles encontrados por Cavalcanti et al. (2004), quando trabalhando com níveis de 0,4 a $4,7 \mathrm{dS} \mathrm{m}^{-1}$, não encontrou diferença significativa. Para a área foliar (AF) ocorreu efeito significativo ao nível de 0,05 , onde os menores valores foram obtidos com níveis de salinidade a partir de $4 \mathrm{dS} \mathrm{m} \mathrm{m}^{-1}$. resultado semelhante foi encontrado para o diâmetro do caule (DC). Para a altura das plantas, o efeito da salinidade afetou apenas no nível mais alto (6 $\mathrm{dS} \mathrm{m}^{-1}$ ). Com relação a fitomassa seca da raiz (FSR), os menores valores foram obtidos com salinidades a partir $4 \mathrm{dS} \mathrm{m} \mathrm{m}^{-1}$, semelhante a fitomassa seca da parte aérea (FSPA). Cavalcanti et al. (2004) observou influencia significativa nos intervalos de 0,4 a $4,7 \mathrm{dS}^{-}$ 1 apenas para matéria seca da parte aérea, enquanto que Silva et al. (2006) verificou que a altura de planta, diâmetro de caule, número de folhas e área foliar sofreram influência drástica da salinidade a partir de $4,7 \mathrm{dS} \mathrm{m}^{-1}$.

Tabela 4 - Resumo da variância e valores médios para número de folhas (NF), área foliar (AF), diâmetro do caule (DIAM), altura (ALT), fitomassa seca da raiz (FSR) e fitomassa seca da parte aérea (FSPA) da mamoneira sob diferentes níveis de salinidade. Mossoró - RN, 2007

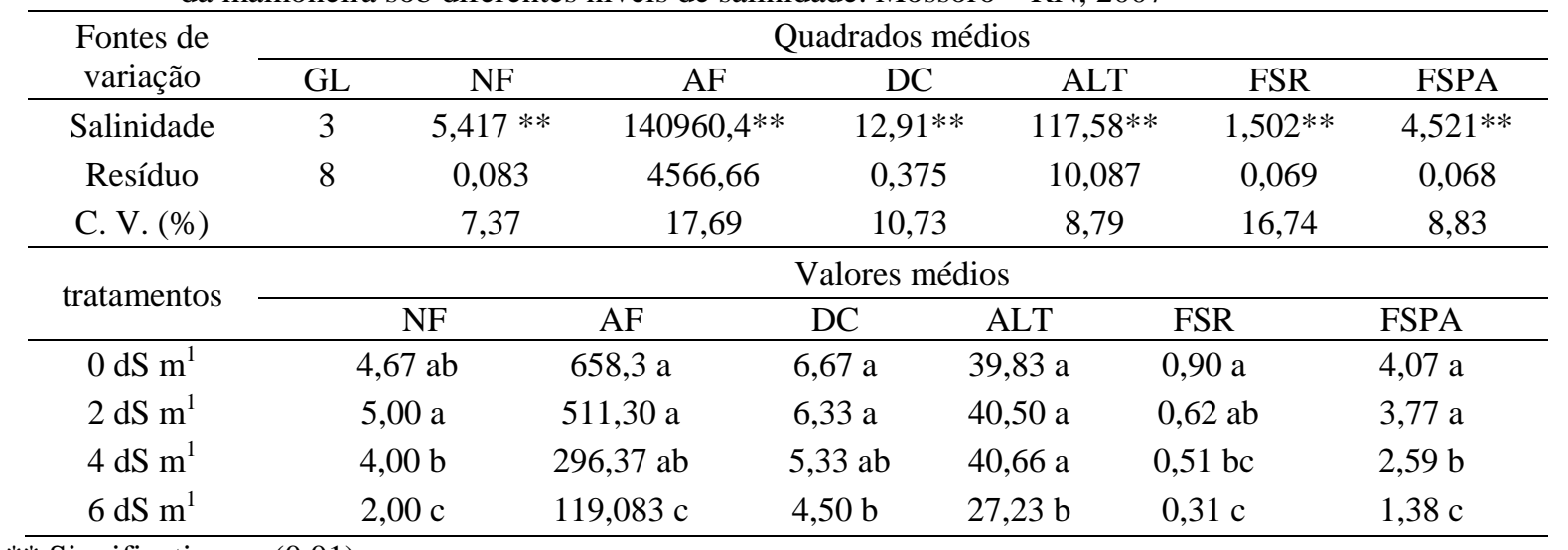

** Significativos a $(0,01)$

médias seguidas com a mesma letra não diferem entre si pelo teste de tukey a 0,05 de probabilidade $\mathrm{AF}=\mathrm{cm}^{2}$, DIAM $=\mathrm{mm}, \mathrm{ALT}=\mathrm{cm}, \mathrm{FSR}$ e FSPA $=$ gramas.

\section{CONCLUSÕES}

Todas as características avaliadas foram influenciadas pelo esterco bovino e pela salinidade. Os melhores desempenhos foram obtidos no tratamento com o teor de esterco na proporção 1:1 e com níveis de salinidade de até $4 \mathrm{dS} \mathrm{m}^{-1}$.

\section{REFERÊNCIAS BIBLIOGRÁFICAS}

AMARO FILHO, J. Contribucion al estúdio del clima del Rio Grande do Norte. ETSIA/UPM, Madrid, 1991. (Tese Doutorado). 


\section{REVISTA VERDE DE AGROECOLOGIA E DESENVOLVIMENTO SUSTENTÁVEL GRUPO VERDE DE AGRICULTURA ALTERNATIVA (GVAA)}

AUCRY, P.; SUASSUNA, P. A. A qualidade da água na irrigação do trópico semi-árido. Um estudo de caso. In: SEMINÁRIO FRANCO-BRASILEIRO DE PEQUENA IRRIGAÇÃO, 1990, Recife. Anais...; Recife PE : 1990, p. 147-153.

AYERS, R.S.; WESTCOT, D.W. A qualidade da água na agricultura. Campina Grande: UFPB, 1991. 218p. (Estudos FAO: Irrigação e Drenagem, 29 Revisado 1).

EMBRAPA, Zoneamento da Mamona no Nordeste, Disponível em; $<$ http://www.cnpa.embrapa.br/produtos/mam ona/zoneamento.html >Acesso em: 01/01/2006.

FAGERIA, N. K. Solos tropicais e aspectos fisiológicos das culturas. Brasília: EMBRAPA/DPU, 1989. 425p. EMBRAPA CNPAF. Documento, 18.

FILGUEIRA, F. A. R. Manual de Olericultura: Agrotecnologia moderna na produção e comercialização de hortaliças. Viçosa, 2000, 402 p.

IZZO, R. NAVARI-IZZO, F.; QUARTACCI, F. Growth and mineral absorption in Maize seedlings as affected by increasing $\mathrm{NaCl}$ concentrations. Journal of Plant Nutrition, v.14, 1991, p.687-699.

LIMA, R. L. S.; SEVERINO, L. S.; SILVA, M. I. L.; JERÔNIMO, J. F.; VALE, L. S.; BELTRÃO, N. E. M. Substratos para produção de mudas de mamoneira compostos por misturas de cinco fontes de matéria orgânica. Ciênc. agrotec., Lavras, v. 30, n. 3, p. 474-479, 2006.
MENDONÇA, V.; ABREU, N. A. A.; SILVA, R. L.; FERREIRA, E. A.; ORBES, M. Y.; TOSTA, M. S. Crescimento de mudas de mamoeiro formosa em substratos com utilização de composto orgânico e superfosfato simples. Ciênc. agrotec., Lavras, v. 30, n. 5, p. 861-868, 2006.

OLIVEIRA, A. B.; QUEIROZ, J. A.; MENEZES, C. H. S. G.; CARTAXO, W. V.; SUASSUNA, N. D. Efeito do tempo de embebição em água e da retirada da carúncula na germinação de sementes de mamona (Ricinnus comunis L.). In: I CONGRESSO BRASILEIRO DE MAMONA. Campina Grande - PB. Anais..., CD-ROM. 2004.

PONTES, H. M. Substratos para a produção de mudas de mamoeiro (Carica papaya L.) na Amazônia Ocidental. Revista da Universidade do Amazonas, Série Ciências Agrárias, Manaus, v. 1, n. 1, p. 57-64, 1991.

RIBEIRO JÚNIOR, J. I. Análises estatísticas no SAEG. Viçosa, Folha de Viçosa, 2001. 301p.

RHOADES, J. D.; KANDIAH, A.; MASHALI, A.M.; Uso de águas salinas para produção agrícola. Campina Grande: UFPB. 2000, 117p. (Estudos da FAO, Irrigação e Drenagem, 48 revisado).

SHANNON, M. C. Adaptation of plants to salinity. Advances in Agronomy, v.60, p.75120, 1997.

STEWART, B.A.; ROBINSON, C.R. Are agroecosystems sustainable in semiarid regions. Advances in Agronomy, v.60, 1997, p.191-228. 